\title{
Changes in Hyphal Morphology due to Chitosan Treatment in Some Fungal Species
}

\author{
Enio Nazaré de Oliveira Junior ${ }^{1 *}$, Itamar Soares de Melo ${ }^{2}$ and Telma Teixeira Franco ${ }^{1}$ \\ ${ }^{I}$ Departmento de Processos Químicos; Faculdade de Engenharia Química; Universidade Estadual de Campinas; \\ Campinas - SP - Brasil. ${ }^{2}$ Embrapa Meio Ambiente; Laboratório de Microbiologia Ambiental; Cx. Postal 69; \\ 13820-000; Jaguariúna - SP - Brasil
}

\begin{abstract}
In this work, changes in the hyphal morphology due to chitosan treatment in some fungal species were studied. Scanning electron microscope (SEM) observations revealed that chitosans with molar fraction of acetyl groups $\left(F_{A}\right.$ 0.16 and 0.18) and degree of polymerization (DP 1,089 and 1,242) had a direct effect on the morphology of the chitosan-treated fungi, reflecting its potential for causing a delay in the growth of Alternaria alternata $(500 \mu \mathrm{g} \times$ $\left.\mathrm{mL}^{-1}\right)$, Botrytis cinerea $\left(1,000 \mu \mathrm{g} \times \mathrm{mL}^{-1}\right)$, Penicillium expansum $\left(1,000 \mu \mathrm{g} \times \mathrm{mL}^{-1}\right)$ and Rhizopus stolonifer $(500$ $\left.\mu \mathrm{g} \times \mathrm{mL}^{-1}\right)$. Mycelial aggregation and structural changes such as excessive branching, swelling of the cell wall and hyphae size reduction were observed in the micrographs.
\end{abstract}

Key words: chitosan, alternative control of fungi, antifungal activity, plant pathogenic fungi, fungal morphology

\section{INTRODUCTION}

Chitin and chitosan (Fig. 1) and oligomers of glucosamine $(\mathrm{GlcN})$ and $\mathrm{N}$-acetyl glucosamine (GlcNAc) as shown in the Figure 2, have been of interest in the past few decades due to their broad range of potential industrial applications. However, only limited attention has been given to food application of these versatile polymers, oligomers and monomers (Shahidi, 1999).

Chitin and chitosan are aminoglucopyranans composed of $\mathrm{N}$-acetylglucosamine (GlcNac) and glucosamine $(\mathrm{GlcN})$ residues. The polymers may be distinguished by their solubility in $1 \%$ aqueous acetic acid. Chitin, containing ca. $>40 \%$ GlcNac residues $\left(\mathrm{F}_{\mathrm{A}}>0.4\right)$ is insoluble, whereas soluble polymers are named chitosan (Peter 2002a). Chitosan has three types of reactive functional groups, an amino group as well as both primary and secondary hydroxyl groups at the C-2, C-3 and C-6 positions respectively (Furusaki et al. 1996). Method mostly used by the industry to produce chitosan from chitin is chemical deacetylation (alkaline hydrolysis); however, chitosan can be obtained by enzymatic deacetylation of chitin (Fig. 1).

Chitin is a natural biopolymer and it is a structural polysaccharide found in the exoskeleton of marine crustaceans (crab and shrimp shells) and insects. It is also widely found in fungi, occurring in Basidiomycota, Ascomycota, and Oomycota, as a component of cell walls and structural membranes of mycelia, stalks, and spores (Peter 2002b). After the discovery of antimicrobial activities of chitosans and its derivatives by Allan and Hadwiger (1979), Kendra and Hadwiger (1984) and Uchida and Ohtakara (1989), many

*Author for correspondence: eniobio@ufsj.edu.br 
researchers have conducted studies in this field (El Ghaouth et al. 1992; Roller and Covill 1999; Ait
Barka et al. 2004; Bautista-Baños et al. 2006; Oliveira-Jr et al. 2008).

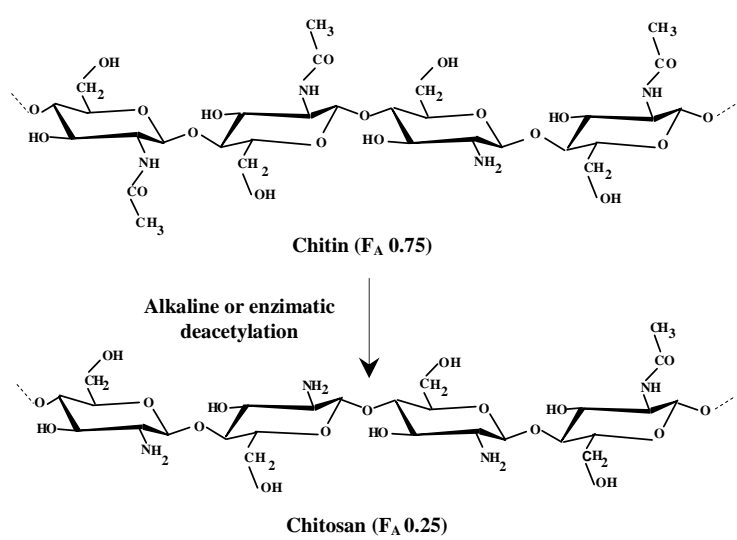

Figure 1 - Structure of chitin and chitosan

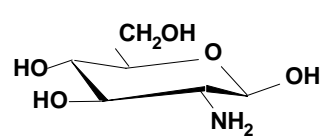

Glucosamine

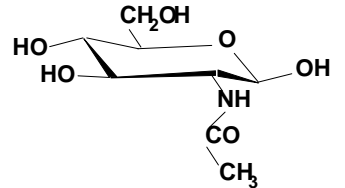

$\mathrm{N}$ - acetylglucosamine

Figure 2 - Structures of glucosamine and $\mathrm{N}$-acetylglucosamine monomers

The filamentous fungi Alternaria alternata, Botrytis cinerea, Penicillium expansum and Rhizopus stolonifer are the causal agents of rots in mango fruits (Prusky et al. 2002), strawberries (El Ghaouth et al. 1991a), apples (Morales et al. 2010) and peaches (Zhang et al. 2007), respectively. In vitro studies have demonstrated that chitosan cause growth inhibition of Alternaria alternata, Botrytis cinerea, Penicillium expansum and Rhizopus stolonifer (Oliveira-Jr. 2006). Chitosan coating on storability and quality of fresh strawberries protected them from infection by Botrytis cinerea and improved their quality (El Ghaouth et al. 1991b). There is a worldwide trend to explore new alternatives that can control postharvest pathogenic diseases, giving priority to methods that reduce disease incidence and avoid negative and side effects on human health as a result of the excessive application of synthetic fungicides. Thus, alternative approaches are necessary to maintain the marketable quality of fresh fruits.
The purpose of this work was to study the effect of chitosan on the hyphal morphology of Alternaria alternata, Botrytis cinerea, Penicillium expansum and Rhizopus stolonifer.

\section{MATERIALS AND METHODS}

\section{Chitosans samples}

Chitosan (molar fraction of acetyl groups $\mathrm{F}_{\mathrm{A}} 0.16$ and degree of polymerization DP 1,089) produced from alkaline deacetylation of chitin (Oliveira-Jr., 2006) and chitosan $\left(F_{A} 0.18\right.$ and DP 1,242) from Primex (Siglufjordur, Iceland) were used. Chitosan $\mathrm{F}_{\mathrm{A}} 0.16$ and DP 1,089 were labeled as chitosan D and chitosan $F_{A} 0.18$ and DP 1,242 was labeled as chitosan P.

\section{Microorganisms and cultivation}

The filamentous fungi used in this study included Alternaria alternata (CCT 2816), Penicillium expansum (CCT 4680) and Rhizopus stolonifer 
(CCT 2002). All of these strains were purchased from André Tosello Foundation Research and Technology (Campinas, SP, Brazil). Botrytis cinerea, an isolate from spoiled grape fruit, was provided by the Institute of Food Technology (Campinas, SP, Brazil). Botrytis cinerea and Penicillium expansum were cultured on potato dextrose agar (PDA) and in malt extract agar (MEA), supplemented with $2 \%(\mathrm{~m} / \mathrm{v})$ of glucose and peptone, respectively, while the Rhizopus stolonifer and Alternaria alternata were both cultured on MEA. In order to achieve the sporulation, the fungi were incubated in Petri dishes $(\varnothing=9 \mathrm{~cm})$ for eight days for A. alternata, $B$. cinerea and $P$. expansum and for four days for $R$. stolonifer at $25^{\circ} \mathrm{C}$ at $100 \mathrm{~cm}$ beneath $\mathrm{Hg}$ lamps with a $12 \mathrm{~h}$ photoperiod. Spores were harvested by pouring the sterile water into the slant and stirring with a vortex for 20 seconds. The suspensions of spores and mycelia were filtered in the cotton. The concentration of spores was assessed by using a hemocytometer (FuchsRosenthal Hell Linie) under light microscope (magnification 400x). The concentration of spores of Rhizopus stolonifer was adjusted to the 10,000 spores $\times \mathrm{mL}^{-1}$ and for $B$. cinerea, A. alternata and $P$. expansum to the 20,000 spores $\times \mathrm{mL}^{-1}$.

\section{Chitosan solution and media preparation}

Stock solutions of chitosans D and P $\left(10 \mathrm{~g} \times \mathrm{L}^{-1}\right)$ were transferred to $1.0 \mathrm{~mL}$ of acetic acid solution $\left(40 \mathrm{mmol} \times \mathrm{L}^{-1}\right)$ in microtubes of $2.0 \mathrm{~mL}$ and shaken in a Vortex mixer for $1 \mathrm{~h}$. The medium used was liquid malt extract $(2 \% \mathrm{~m} / \mathrm{v})$ from Merck (Darmstadt, Germany). The chitosan concentrations in the media were $500 \mu \mathrm{g} \times \mathrm{mL}^{-1}$ for A. alternata and $R$. stolonifer and $1,000 \mu \mathrm{g} \times$ $\mathrm{mL}^{-1}$ for $B$. cinerea and $P$. expansum. The final pHs were 4.9 (control medium), 5.4 (acetic acid, chitosan and medium) and 4.4 (control of acetic acid and medium). In previously autoclaved microtubes of $2.0 \mathrm{~mL}$ appropriate volume of chitosan stock or acetic acid solutions $(50 \mu \mathrm{L}$ for A. alternata and $R$. stolonifer and $100 \mu \mathrm{L}$ for $B$. cinerea and $P$. expansum) was added. The microtubes containing $50 \mu \mathrm{L}$ were supplemented with autoclaved distilled water to make the volume as $100 \mu \mathrm{L}$. In all the microtubes $890 \mu \mathrm{L}$ of malt extract medium was added. The spore suspension was first vortex-mixed vigorously and $10 \mu \mathrm{L}$ of spore suspensions were transferred to the microtubes. After inoculation, the microtubes were closed and incubated at $25^{\circ} \mathrm{C}$ under stirring of 200 o.p.m (orbits per minute) for three days for $R$. stolonifer and five days for A. alternata, B. cinerea and $P$. expansum. The experiments were carried out with three repetitions.

\section{Scanning electron microscopy (SEM)}

Scanning electron microscopy was carried out in accordance to the methodology described by Melo and Faull (2004) on the materials described below. In case of control suspension, the hyphae was removed from the media by using the clamp and the suspension treated with chitosans were filtered in Millipore membrane PTFE hydrophilic of pore size $0.45 \mu \mathrm{m}$ and $\varnothing=13 \mathrm{~mm}$ (São Paulo, SP, Brazil). The samples were fixed by immersion in $2.5 \%(\mathrm{v} / \mathrm{v})$ glutaraldehyde in $0.1 \mathrm{~mol} \mathrm{~L}^{-1}$ sodium cacodylate buffer $\mathrm{pH} 7.0$ for $1 \mathrm{~h}$, washed three times in $0.1 \mathrm{~mol} \mathrm{~L}^{-1}$ sodium cacodylate buffer $\mathrm{pH}$ 7.0 , post-fixed with $1 \%(\mathrm{~m} / \mathrm{v})$ osmium tetroxide in the same buffer for $1 \mathrm{~h}$ and washed three times again in $0.1 \mathrm{~mol} \mathrm{~L}^{-1}$ sodium cacodylate buffer $\mathrm{pH}$ 7.0. The material was then dehydrated in a crescent acetone series $(10,25,40,60,75,85,95$ and $100 \%, \mathrm{v} / \mathrm{v})$ with $15 \mathrm{~min}$ per change. The specimens were transferred to a critical point dryer to complete the drying process with carbon dioxide as a transition fluid. Then, the specimens obtained were mounted on aluminum stubs, with a double-stick carbon tape and sputter-coated with gold and observed using a field emission scanning electron microscope, Leo 982 (Zeiss + Leica).

\section{RESULTS AND DISCUSSION}

Results after five days of cultivation at $25^{\circ} \mathrm{C}$ for $A$. alternata (Fig. 3), B. cinerea (Fig. 4) and $P$. expansum (Fig. 5) and after three days for $R$. stolonifer (Fig. 6) showed that chitosan amendment caused aggregation and morphological changes of mycelia which were coated with chitosan. Aggregation, excessive mycelial branching and hyphae size reduction of all fungi treated with chitosan were observed. A. alternata, $B$. cinerea and $R$. stolonifer treated with chitosan besides to have the morphological changes mentioned before, also showed abnormal shapes and swelling in their mycelia (Figures 3, 4 and 6). El Ghaouth et al. (1992) reported that chitosan $\left(3,000 \mu \mathrm{g} \times \mathrm{mL}^{-1}, \mathrm{~F}_{\mathrm{A}} 0,99\right.$, DP not shown) caused severe morphological changes in $R$. stolonifer 
which was characterized by excessive branching and swelling of the cell wall; however, in $B$. cinerea and $A$. alternata that morphological changes were not observed. The chitosan $(500 \mu \mathrm{g}$ $\times \mathrm{mL}^{-1}$ in A. alternata and R. stolonifer; $1,000 \mu \mathrm{g}$ $\times \mathrm{mL}^{-1}$ in $B$. cinerea and $P$. expansum) labeled as sample $\mathrm{D}\left(\mathrm{F}_{\mathrm{A}} 0.16\right.$, DP 1,089) and labeled as sample $\quad \mathrm{P} \quad\left(\mathrm{F}_{\mathrm{A}} \quad 0.18, \quad \mathrm{DP} \quad 1,242\right)$ induced considerable morphological changes in all the four fungi tested (Figures 3 to 6). These diverging results might have originated from different methods of chitosan preparation that had a significant effect on the $\mathrm{DP}$ and $\mathrm{F}_{\mathrm{A}}$ of the resulting biopolymers and thereby, their antimicrobial activities.

Chitosans on the surface of $R$. stolonifer mycelia were observed in the scanning electron micrographs (Figures $6 \mathrm{C}$ and D).
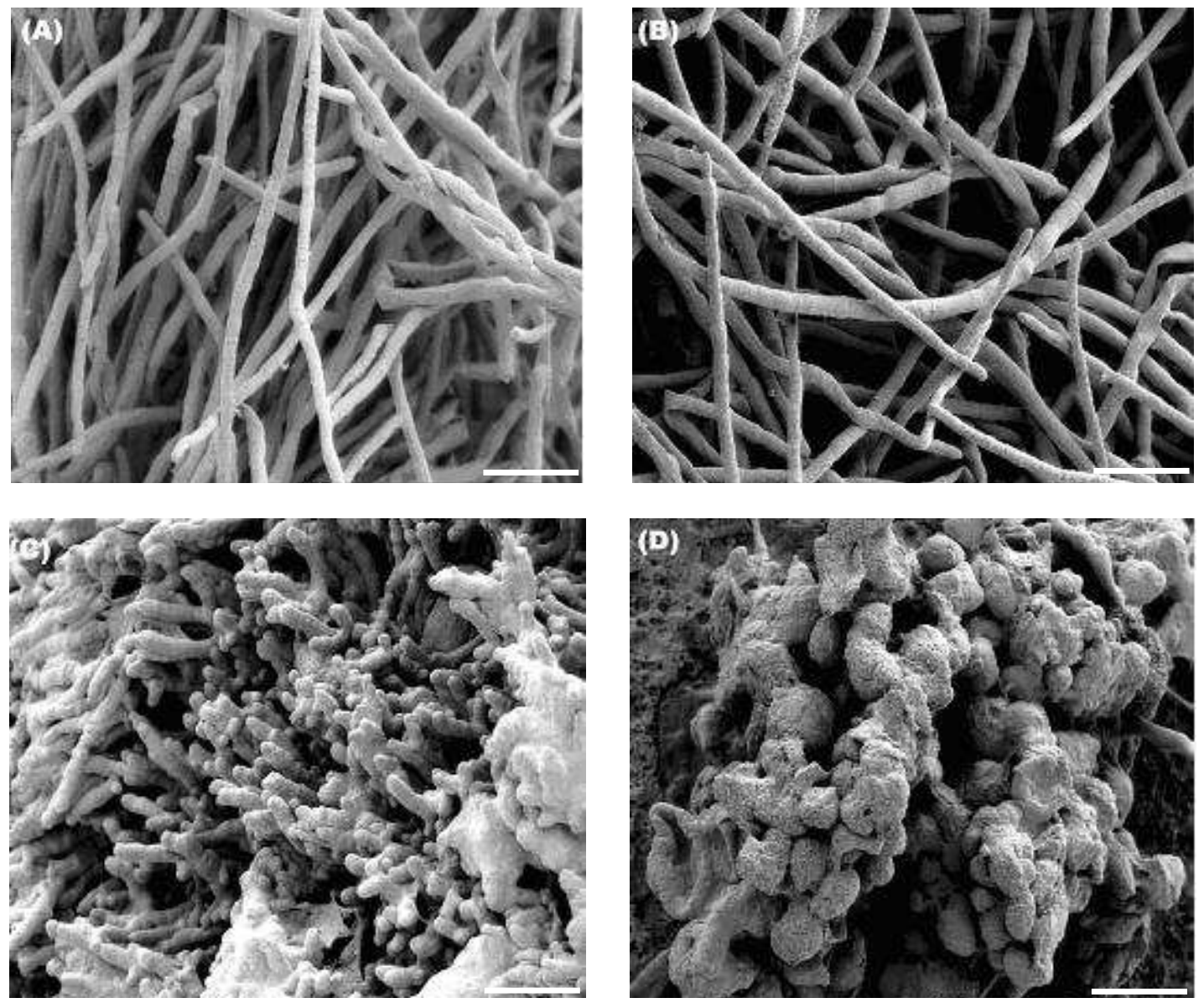

Figure 3 - Scanning electron micrographs of Alternaria alternata mycelia after 5 days of cultivation at $25{ }^{\circ} \mathrm{C}$. (A) Control media, (B) acetic acid control $\left(40 \mathrm{mmol} \times \mathrm{L}^{-1}\right)$, (C) medium amended with chitosan $\mathrm{D}\left(500 \mu \mathrm{g} \times \mathrm{mL}^{-1}\right)$ and $(\mathrm{D})$ medium amended with chitosan $\mathrm{P}$ $\left(500 \mu \mathrm{g} \times \mathrm{mL}^{-1}\right)$. Bars $=20 \mu \mathrm{m}$.

In further studies, image analysis was used to measure the effect of chitosan on the morphology of fungi, such as $F$. oxysporum f. sp. radicislycopersici, and $S$. sclerotiorum treated with chitosan. These studies showed excessive mycelial branching, abnormal shapes, swelling, and hyphae size reduction (Benhamou 1992; Cheah et al. 1997). Large vesicles or empty cells devoid of cytoplasm in the mycelium of $B$. cinerea, treated with chitosan, were observed by Ait Barka et al. (2004). 

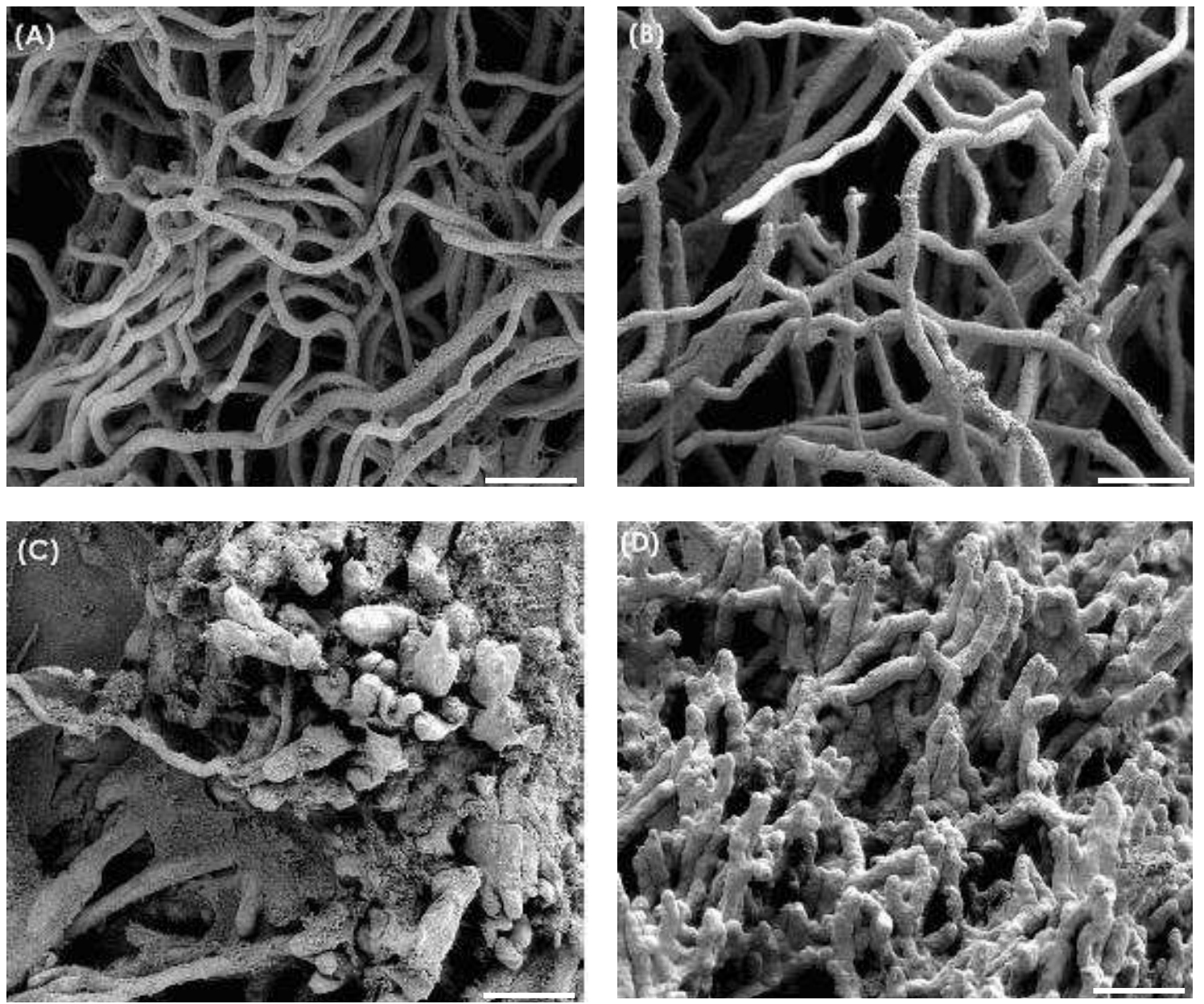

Figure 4 - Scanning electron micrographs of Botrytis cinerea mycelia after 5 days of cultivation at $25^{\circ} \mathrm{C}$. (A) Control media, (B) acetic acid control $\left(40 \mathrm{mmol} \times \mathrm{L}^{-1}\right),(\mathrm{C})$ medium amended with chitosan $\mathrm{D}\left(1,000 \mu \mathrm{g} \times \mathrm{mL}^{-1}\right)$ and (D) medium amended with chitosan $\mathrm{P}(1,000 \mu \mathrm{g}$ $\left.\times \mathrm{mL}^{-1}\right)$. Bars $=20 \mu \mathrm{m}$.

The micrographs showed that chitosan amendment caused aggregation of mycelia that were coated with this polymer. Similar morphological anomalies caused by chitosan coating on the mycelial surface of fungi studied, suggested that chitosan layer around the spores or hyphae could cause difficulty for the entry of nutrients in the cells.

The exact mechanism by which the higher chitooligosaccharides and chitosans exert antimicrobial activity is unknown. Based on the observation that the fungistatic activity was higher at lower $\mathrm{pH}$, it was assumed that the toxicity was correlated, besides to optimum DP, to the cationic charge of the oligosaccharides (Torr et al. 2005). The present study indicated that reasons also could be important for the growth rates inhibition, i.e., enzymatic uptake of simple carbohydrates by the permeases could temporally be blocked by the presence of the large oligosaccharides (Oliveira-Jr. et al. 2008). Several fungi systems (such as cellulase containing) are usually controlled by the inducers and glucose or catabolite repression, and the expression of enzymes to hydrolyze larger molecules to soluble oligosaccharides (low DP). After cellulose and large molecules are degraded, a large amount of glucose is liberated, which causes catabolite repression (Suto and Tomita 2001).

Chitin hydrolyzing enzymes could be similarly regulated, controlled by the inducers and short chain molecules. Amaretti et al. (2007) have demonstrated carbohydrate preferences in bacteria resulting from different distributions of carbon fluxes through the fermentative pathway, where it substrate selectivity was observed based on the 
degree of polymerization, when shorter saccharides were the first to be consumed, while a delay was observed until longer oligosaccharides were utilized (Oliveira-Jr. et al. 2008).

A number of possible mechanisms for the antimicrobial action of chitosan have been proposed, mostly based on the positive charge conferred by protonation of free amino groups at acidic $\mathrm{pH}$, although the exact mechanism of action is still unknown.

A polycationic chitosan or oligomer can potentially interact with negatively charged fungal cell membrane components (i.e., proteins, phospholipids), thus interfering with the normal growth and metabolism of the fungal cells (Bautista-Baños et al. 2006; Fang et al. 1994; Shahidi et al. 1999). Roller and Covill (1999) reported that amino groups in chitosan have the ability to interact with a multitude of anionic groups on the yeast cell wall surface, thereby forming an impervious layer around the cell. Because of its property to form the films, chitosan may, thus, act as a barrier (i.e. anionic groups) and consequently, reducing their availability to a level that will not sustain growth of the pathogen form the films (Bautista-Baños et al. 2006). The present results suggested that this barrier to water soluble nutrients could be most effective for chitosans of lower molar mass and low $\mathrm{F}_{\mathrm{A}}$, since it was observed that the water permeability of chitosan films was $50 \%$ reduced when molar mass of the original chitosan was reduced from $235 \mathrm{kDa}$ (DP 1,383 ) to approximately $13.7 \mathrm{kDa}$ (DP 45), which was also reported by Yoshida et al. (2008).
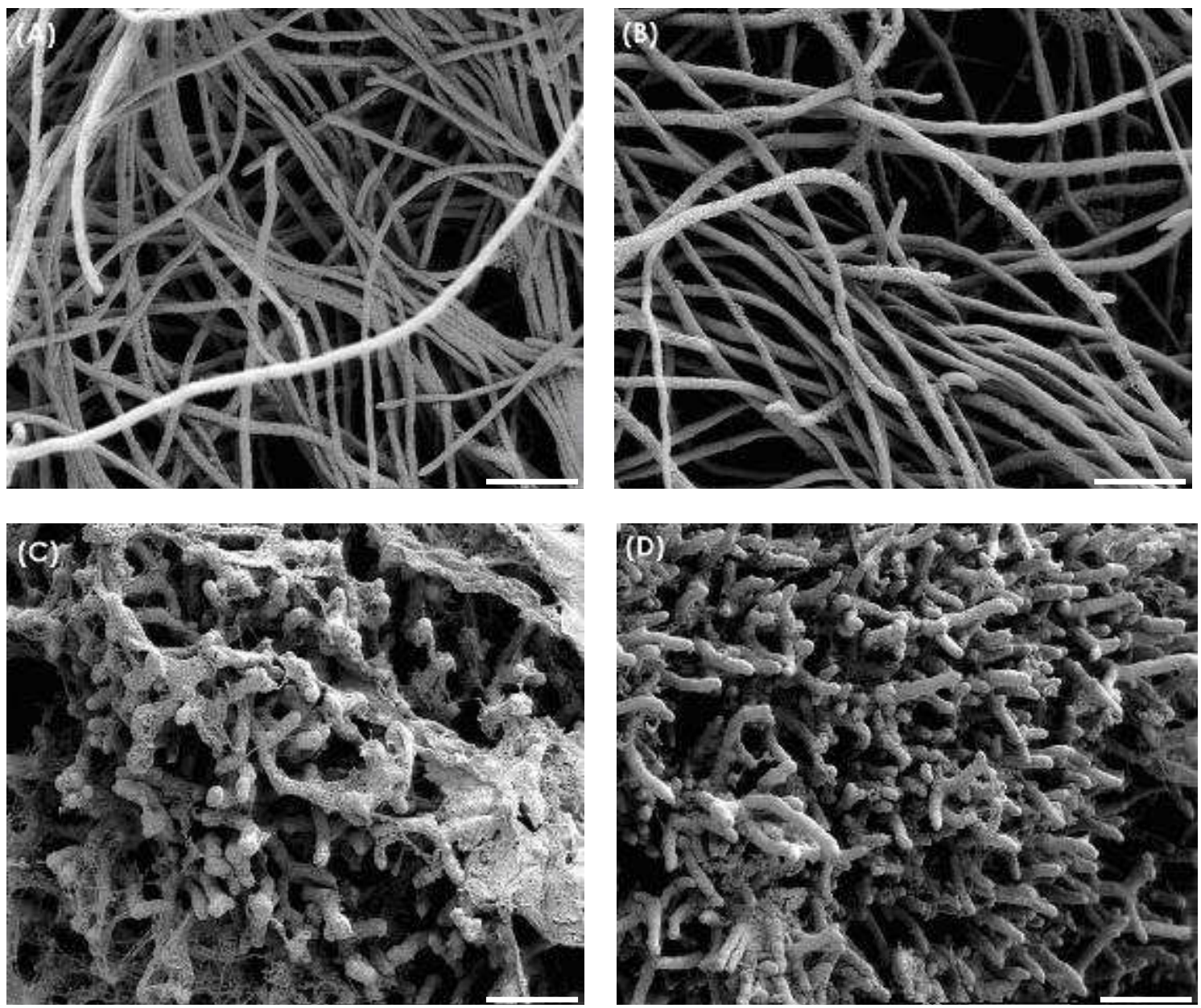

Figure 5 - Scanning electron micrographs of Penicillium expansum mycelia after 5 days of cultivation at $25{ }^{\circ} \mathrm{C}$. (A) Control media, (B) acetic acid control $\left(40 \mathrm{mmol} \times \mathrm{L}^{-1}\right),(\mathrm{C})$ medium amended with chitosan $\mathrm{D}\left(1,000 \mu \mathrm{g} \times \mathrm{mL}^{-1}\right)$ and (D) medium amended with chitosan $\mathrm{P}\left(1,000 \mu \mathrm{g} \times \mathrm{mL}^{-1}\right)$. Bars $=20 \mu \mathrm{m}$. 

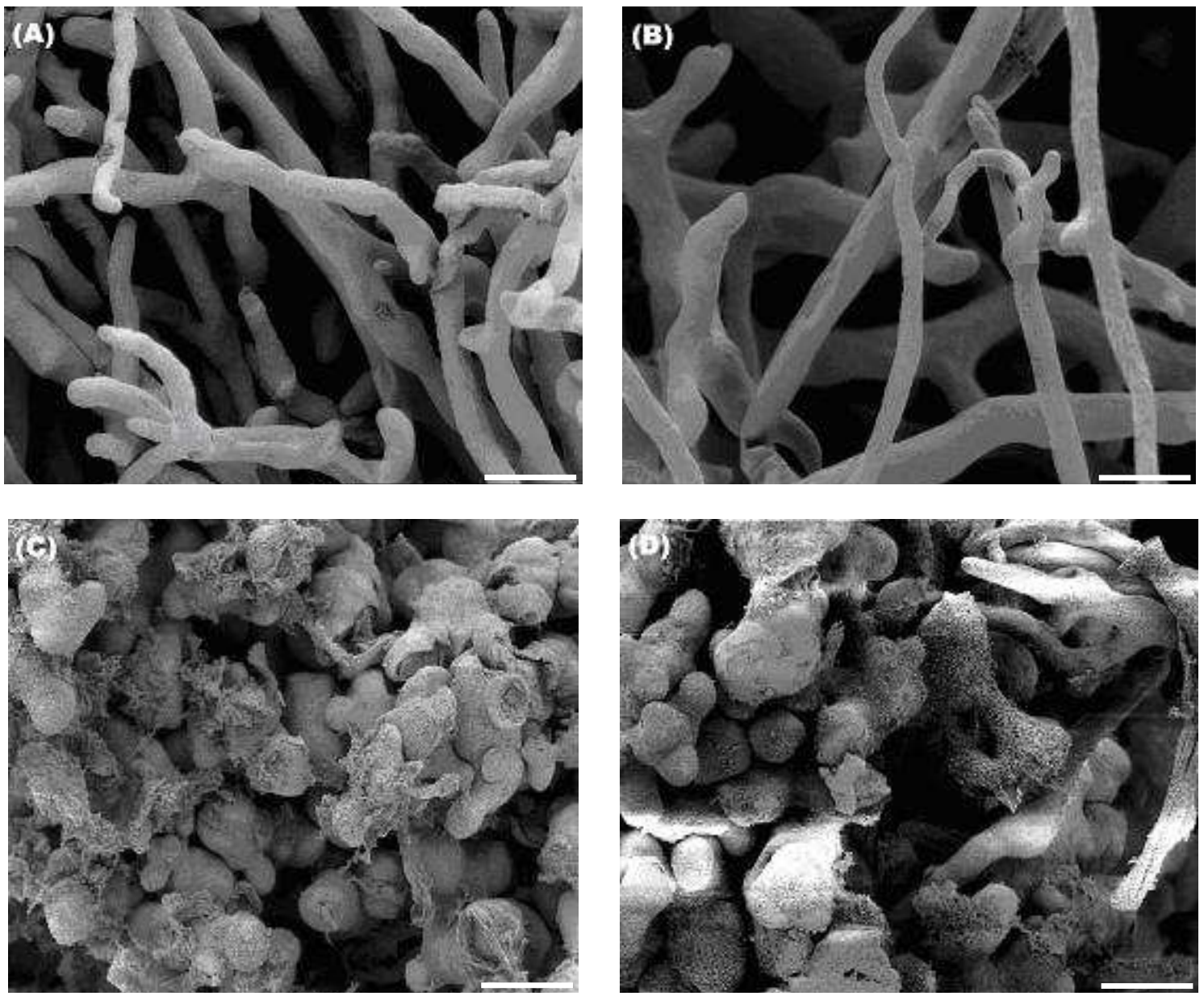

Figure 6 - Scanning electron micrographs of Rhizopus stolonifer mycelia after 3 days of cultivation at $25^{\circ} \mathrm{C}$. (A) Control media, (B) acetic acid control $\left(40 \mathrm{mmol} \times \mathrm{L}^{-1}\right),(\mathrm{C})$ medium amended with chitosan $\mathrm{D}\left(500 \mu \mathrm{g} \times \mathrm{mL}^{-1}\right)$ and (D) medium amended with chitosan $\mathrm{P}\left(500 \mu \mathrm{g} \times \mathrm{mL}^{-1}\right)$. Bars $=20 \mu \mathrm{m}$.

Chitosan coating observed on the surface of the mycelia suggested that the fungal growth inhibition could be explained by a direct interaction of chitosan on the fungal cell wall as a consequence of polycationic nature of chitosan. Oliveira-Jr. (2006) have observed that chitosan samples with low $\mathrm{F}_{\mathrm{A}}$ (high concentration of free amino groups protonated) and large DP (degree of polymerization) were most effective against the phytopathogenic fungi tested, while chitosan with high $F_{A}$ did not have the ability to inhibit the fungal growth in vitro. In another study, OliveiraJr. et al. (2008) have demonstrated that chitooligosaccharides of eight degree of polymerization (DP) were not notably inhibitory to any of the fungi. On the other hand, higher chitooligosaccharides (DP 10 and DP 12) showed initially inhibitory effects, which seemed to be more pronounced at a lower $\mathrm{F}_{\mathrm{A}}$.

The $\mathrm{pH}$ value of mycelial suspension, before its fixation and post-fixation, was about 5.4 and after this, it changed to 7.0. In the $\mathrm{pH}$ 5.4, chitosan was soluble in the mycelial suspension that was filtered in Millipore membrane (pore size $0.45 \mu \mathrm{m}$ ). Bound chitosan on the fungal cell wall was precipitated at a $\mathrm{pH} 7.0$ and, then, chitosan coating was formed. This observation was supported by the scanning electron microscopy for all the fungi treated with chitosan. The micrographs of $P$. expansum previously treated with chitosan viewed in high magnification of $10,000 \times$ showed the chitosan coating formed on surface of the mycelia (Fig. 7 A).

The results demonstrated that chitosan acetate was 
effective in restricting the fungal growth of filamentous fungi (Oliveira-Jr 2006) by causing a fungistatic inhibition effect as observed by the scanning electron microscopy.

In case of A. alternata, it was common to observe some spores with germ tubes inhibition as shown in Figure 7 B.

The aggregates of chitosans were observed in the micrographs on media amended with chitosans D and $\mathrm{P}$ on the surface of Millipore membranes that were fixed and post-fixed as described before

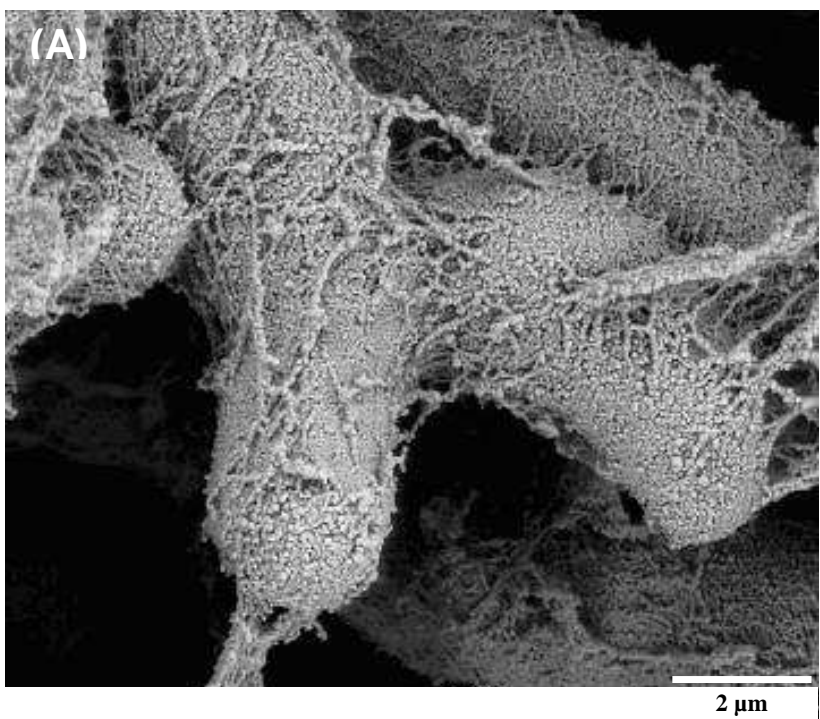

(Figures $8 \mathrm{~A}$ and $\mathrm{C}$ ). As shown in the Figures $8 \mathrm{~B}$ and $\mathrm{D}$, different aggregates of chitosans were observed in the micrographs on the media amended with the same chitosans on Millipore membrane surface. These chitosans were not fixed and post-fixed; they were filtered and dried at room temperature for one day. The difference observed in the aggregate of chitosans could be related to the $\mathrm{pH} 7.0$ of the sodium cacodylate buffer used for SEM preparation that became chitosan insoluble.

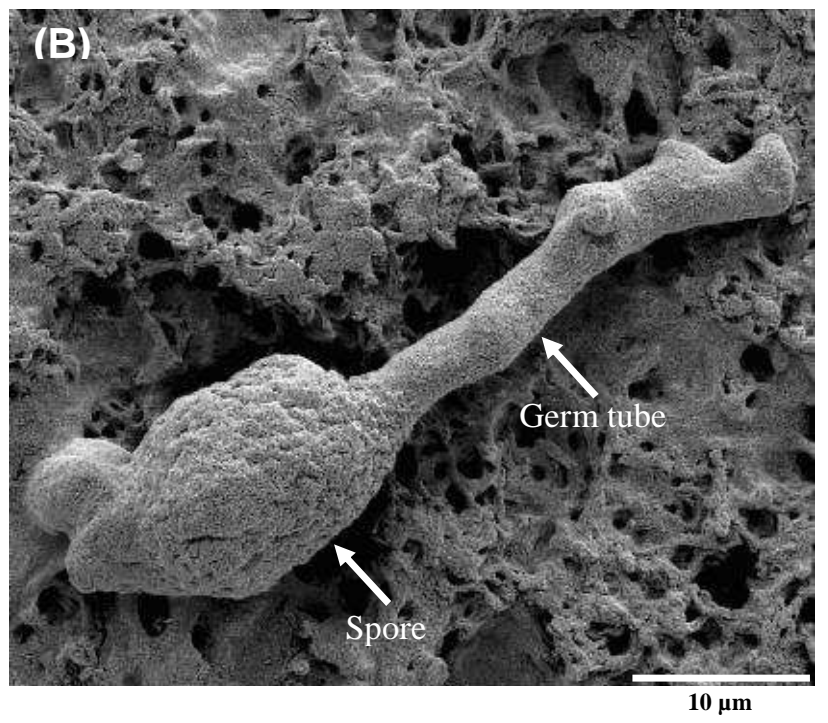

Figure 7 - (A) Scanning electron micrograph of Penicillium expansum mycelia after 5 days of culture at $25^{\circ} \mathrm{C}$ with medium amended with chitosan D $\left(1,000 \mu \mathrm{g} \times \mathrm{mL}^{-1}\right)$. (B) Spore and germ tube of Alternaria alternata with medium amended with chitosan $\mathrm{P}(500 \mu \mathrm{g} \times$ $\mathrm{mL}^{-1}$ ). Figure 7 (A) bar $=2 \mu \mathrm{m}$; Figure 7 (B) bar $=10 \mu \mathrm{m}$.
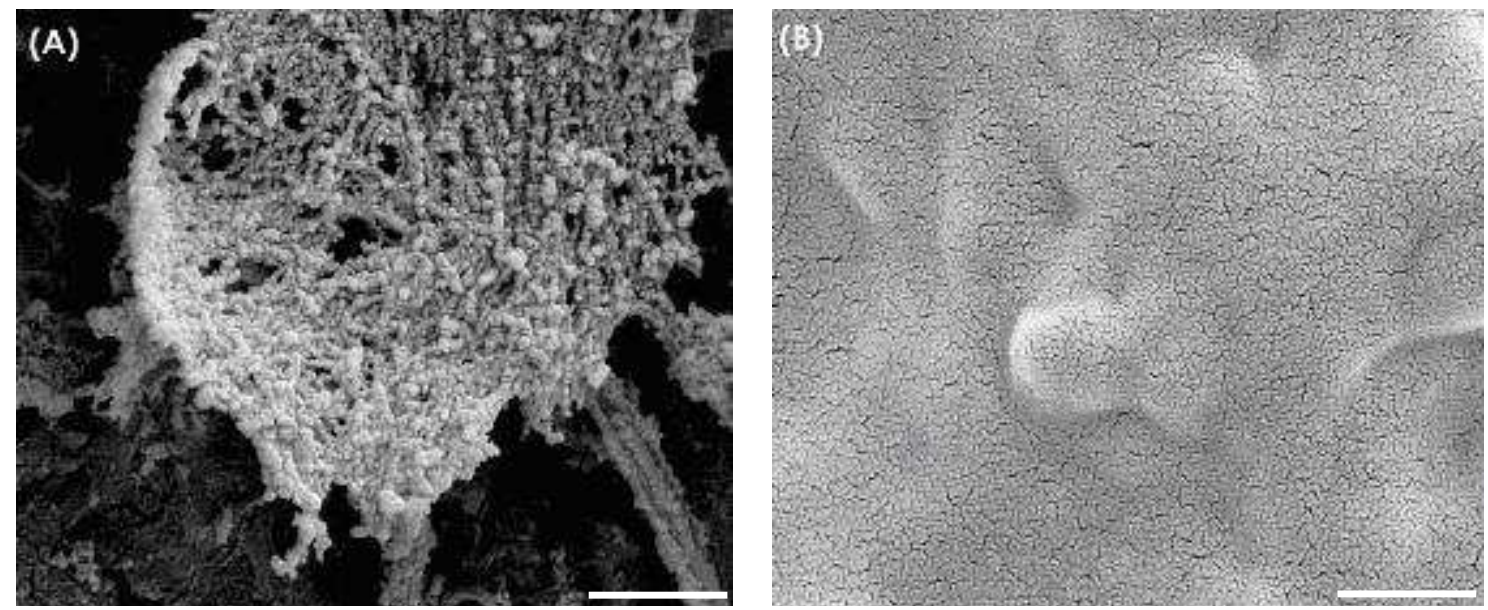

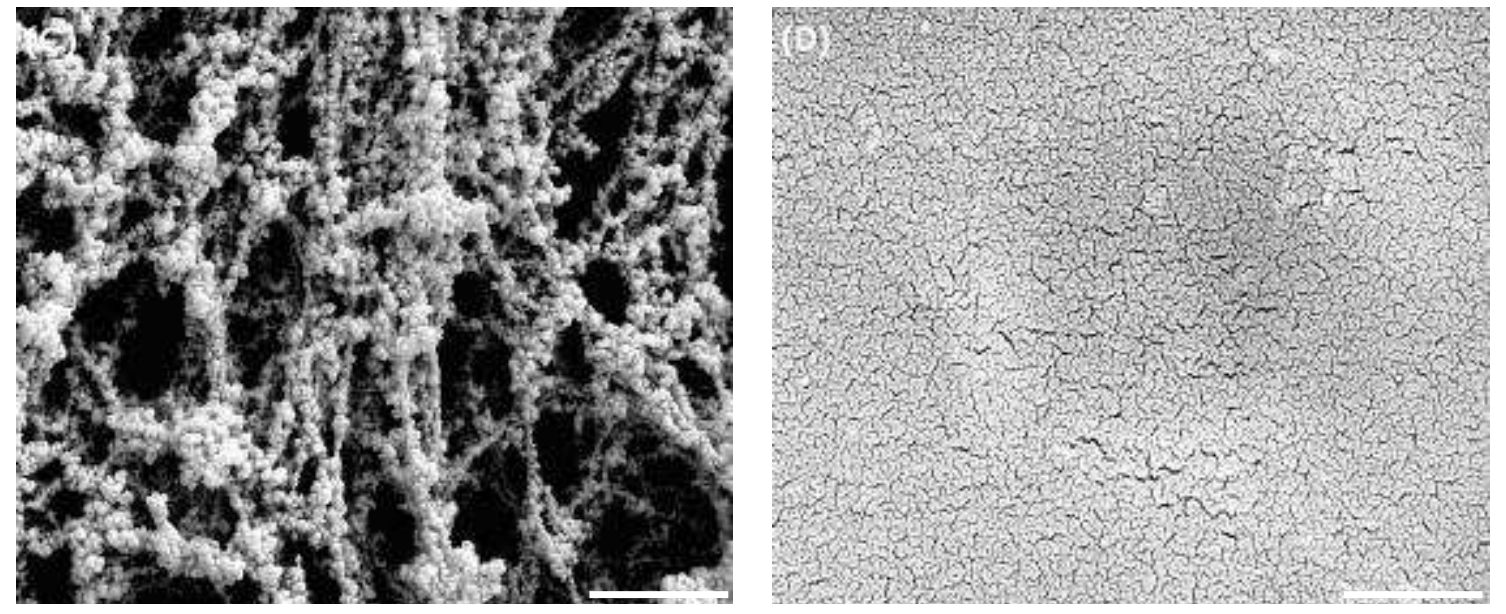

Figure 8 - Scanning electron micrographs of medium amended with $1,000 \mu \mathrm{g} \times \mathrm{mL}^{-1}$ of chitosan $\mathrm{D}$ (A) filtered and fixed as described in the item 2.6 (B) only filtered; $1,000 \mu \mathrm{g} \times \mathrm{mL}^{-1}$ of chitosan P (C) filtered and fixed as described in the item 2.6 and (D) only filtered. Bars $=2 \mu \mathrm{m}$.

\section{CONCLUSIONS}

The SEM revealed that chitosan could be used to delay the fungal growth of the following filamentous fungi: A. alternata, $B$. cinerea, $P$. expansum and $R$. stolonifer. The micrographs showed that chitosans caused mycelial aggregation and structural changes as excessive branching, swelling of the cell wall and hyphae size reduction.

\section{ACKNOWLEDGMENTS}

Financial support by the Brazilian funding agencies FAPESP, CAPES and CNPq is gratefully acknowledged, as also to the PROBRAL programme (CAPES/DAAD) and to the European Commission (ALFA Programme, II-0259-FA-FC POLYLIFE).

\section{REFERENCES}

Ait Barka E, Eullaffroy P, Clément C, Vernet G. Chitosan improves development, and protects Vitis vinifera L. against Botrytis cinerea. Plant Cell Rep. 2004; 22: 608-614.

Allan CR, Hadwiger LA. The fungicidal effect of chitosan on fungi of varying cell composition. Exp Mycol. 1979; 3: 285-287.
Amaretti A, Bernardi T, Tamburini E, Zanoni S, Lomma M, Matteuzzi D, Rossi M. Kinetics and metabolism of Bifidobacterium adolescentis MB 239 growing on glucose, galactose, lactose, and galactooligosaccharides. Appl Environ Microbiol. 2007; 11: 3637-3644.

Bautista-Baños S, Hernandez-Lauzardo AN, Velázquez-del Valle MG, Hernández-López M, Bravo-Luna L, Ait Barka E, et al. Chitosan as a potential natural compound to control pre and postharvest diseases of horticultural commodities. Crop Prot. 2006; 25: 108-118.

Benhamou N. Ultrastructural and cytochemical aspects of chitosan on Fusarium oxysporum f. sp. radicislycopersici, agent of tomato crown and root rot. Phytopathology. 1992; 82: 1185-1193.

Cheah LH, Page BBC. Chitosan coating for inhibition of Sclerotinia rot of carrots. N Z J Crop Hortic Sci. 1997; 25: 89-92.

El Ghaouth A, Arul J, Ponnampalam R, Boulet M. Chitosan coating effect on storability and quality of fresh strawberries. J Food Sci. 1991a; 56: 1618-1620.

El Ghaouth A, Arul J, Ponnampalam R, Boulet M. Use of chitosan coating to reduce water loss and maintain quality of cucumber and bell pepper fruits. J Food Process Preservat. 1991b; 15: 359-368.

El Ghaouth A, Arul J, Asselin A, Benhamou N. Antifungal activity of chitosan on post-harvest pathogens: induction of morphological and cytological alterations in Rhizopus stolonifer. Mycol Res. 1992; 96: 769-779.

Fang SW, Li CF, Shih DYC. Antifungal activity of chitosan and its preservative effect on low sugar candied kumquat. J Food Protection. 1994; 56: 136140. 
Furusaki E, Ueno Y, Sakairi N, Nishi N, Tokura S. Facile preparation and inclusion ability of a chitosan derivative bearing carboxymethyl- $\beta$-cyclodextrin. Carbohydr Polym. 1996; 9: 29-34.

Kendra DF, Hadwiger LA. Characterization of the smallest chitosan oligomer that is maximally antifungal to Fusarium solani and elicits pisatin formation by Pisum sativum. Exp Mycol. 1984; 8: 276-281.

Melo IS, Faull JL. Scanning electron microscopy of conidia of Thichoderma stromaticum, a biocontrol agent of witches broom disease of cocoa. Braz J Microbiol. 2004; 35: 330-332.

Morales H, Marín S, Ramos AJ, Sanchis V. Influence of post-harvest technologies applied during cold storage of apples in Penicillium expansum growth and patulin accumulation: A review. Food Control. 2010; 21: 953-962.

Oliveira-Jr EN. Caracterização dos efeitos de quitosanas na inibição de fungos fitopatogênicos [PhD Thesis]. Campinas (SP): State University of Campinas; 2006.

Oliveira-Jr EN, El Gueddari NE, Moerschbacher BM, Peter MG, Franco TT. Growth of phytopathogenic fungi in the presence of partially acetylated chitooligosaccharides. Mycopathologia. 2008; 166: 163-174.

Peter MG. Chitin and chitosan from animal sources. In: Vandamme EJ, De Baets S, Steinbüchel A, editors. Biopolymers, Polysaccharides II: Polysaccharides from Eukaryotes. Weinheim: Wiley-VCH; 2002a. p. 481-574.

Peter MG. Chitin and Chitosan in Fungi. In: Vandamme EJ, De Baets S, Steinbüchel A, editors. Biopolymers, Polysaccharides II: Polysaccharides from Eukaryotes. Weinheim: Wiley-VCH; 2002b. p. 123-157.

Prusky D, Shalom Y, Kobiler I, Akerman M. Fuchs, Y. The level of quiescent infection of Alternaria alternata in mango fruits at harvest determines the postharvest treatment applied for the control of rots during storage. Postharvest Biol Technol. 2002; 25: 339-347.
Roller S, Covill N. The antifungal properties of chitosan in laboratory media and apple juice. Int $J$ Food Microbiol. 1999; 47: 67-77.

Shahidi F, Arachchi JKV, Jeon YJ. Food applications of chitin and chitosans. Trends Food Sci Technol. 1999; 2: 37-51.

Suto M, Tomita F. Induction, catabolite repression mechanisms of cellulase in fungi. J Biosci Bioeng. 2001; 92: 305-311.

Torr KM, Chittenden C, Franich RA, Kreber B. Advances in understanding bioactivity of chitosan and chitosan oligomers against selected woodinhabiting fungi. Holzforschung. 2005; 59: 559-567.

Uchida Y, Izume M, Ohtakara A. Preparation of chitosan oligomers with purified chitosanase and its application. In: Skjak-Braek G, Anthonsen T, Sandford P, editors. Chitin and chitosan: sources, chemistry, biochemistry, physical properties and applications. London: Elsevier; 1989. p. 373-382.

Yoshida CMP, Oliveira-Jr EN, Franco TT. Chitosan tailor-made films: the effects of additives on barrier and mechanical properties. Packing Technol Sci. 2008; 22: 161-170.

Zhang H, Wang L, Zheng X, Dong Y. Effect of yeast antagonist in combination with heat treatment on postharvest blue mold decay and Rhizopus decay of peaches. Int J Food Microbiol. 2007; 115: 53-58.

Received: March 10, 2011; Revised: July 01, 2011; Accepted: March 28, 2012. 